Research Article

JSARD

ISSN: 2470-850X Online

Vol. 5, Issue 1 (2020), pp. 18-23

ISARD.org

\title{
Reflective Writing in a Principal Preparation Program
}

\author{
James Wright, San Diego State University \\ Douglas Fisher, San Diego State University \\ Nancy Frey, San Diego State University
}

\begin{abstract}
Reflective writing has become part of a vast spectrum of professional practices across academia, which includes the hard sciences-notably in the fields of medicine and nursing, as well as in the humanities, including social work, higher education, teacher education, and educational leadership. In this article, we seek to describe the results of an investigation in the preparation of school leaders through reflective writing. Our engagement with selfreflective writing is explicitly designed to help future educational leaders identify and promote the skills that help leaders identify inequity in schools. The preliminary administrative credential program in this study is rooted in efforts to prepare equity-driven school leaders who integrate dispositions, concepts, and actions into their daily practice.
\end{abstract}

Keywords: educational leadership, reflective writing, principal preparation program

Reflective writing is a practice utilized across a vast spectrum of professional preparation programs in academia including the hard sciences, medicine and nursing, as well as the humanities, social work, higher education, teacher education, and educational leadership (Bowman \& Addyman, 2014; Coleman \& Willis, 2015; Fendler, 2003; Hoover, 1994; Mahlanze \& Sibiya, 2017; McGuire, Lay, \& Peters, 2009; Naber \& Wyatt, 2014; Ryan, 2011; Schwartz et al., 2009). McGuire et al. (2009) argued that humanities-based pedagogical approaches such as reflective writing techniques are useful in higher education to prepare candidates who are grounded in the values of their field, beyond the knowledge and professional skills required. Schwartz et al. (2009) highlighted that recent humanities-based trends in medical education are an acknowledgment of their value to the medical community. Reflective writing has become an essential component in the field of nursing and to nursing education programs (Bowman \& Addyman, 2014; Coleman \& Willis, 2015). Scholars found some types of reflective writing in nursing produced enhanced critical thinking, problem solving, and analytical skills, and left students with a sense of freedom of expression (Coleman \& Willis, 2015; Hoover, 1994; Naber \& Wyatt, 2014; Mahlanze \& Sibiya, 2017).

Reflective writing is also considered prominent and productive in teacher-education training programs (Fendler, 2003; Hoover, 1994). Hoover's (1994) evaluation of the field-experience of preservice teachers in a university teacher training program found that students' reflective writing assignments led to higher level thinking as well as more explicit cognitive processes in constructing knowledge about teaching and learning. In the field of educational leadership, reflection is portrayed as a means of developing expertise, enhancing instructional strategies, and correcting past leadership errors toward more effective educational leadership preparation, and thus more effective practice in the field (Boud, Keogh, \& Walker, 2013; Bryk, Sebring, Allensworth, Luppescu, \& Easton, 2010; Campbell, 1979; Egalite, Fusarelli, \& Fusarelli, 2017; Furman, 2012; Hart, 1993b; Khalifa, 2018; Kottkamp, 2011; Lindle, 2009; Pounder \& Johnson, 2007; Short \& Rinehart, 1993; Wang et al., 2018).

In this article, we seek to describe the results of an investigation in the preparation program of school leaders where reflective writing was reconceived as a means to develop effective practices. More specifically, our engagement with self-reflective writing is explicitly designed to help future educational leaders recognize and promote the skills that help identify their role in reproducing inequity in schools. The preliminary administrative credential program in this 
study is rooted in efforts to prepare equity-driven school leaders who integrate dispositions, concepts and actions into their daily practice to confront institutional barriers (Marshall \& Fisher, 2018).

\section{Review of Literature}

Hart (1993) reminds us that "the idea that reflection can be used to turn experience into learning is not new" (p. 340). Hart further argues that Dewey and progressive era educational philosophies, the cognitive sciences, and problem-solving disciplines draw from the tradition of reflection. In Reflection: Turning Experience into Learning, Boud et al. (2013) engaged with higher education professors from a range of disciplines, including management, psychology, and medicine, to conceptualize the benefits of reflection in education in their respective fields. The authors noted agreement among colleagues on the value of the metaphor of the picture and the frame as a way of describing what candidates must do to truly reflect:

There are two things the teacher can do: He can frame problems through the point of view from which he examines them; and he can present particular ways of picturing what is seen through the ways he makes sense of what he sees. (Boud, et al. 2013, p. 117)

Thus, reflection demands more than simply recounting what one has experienced (Schön, 1983). To simply recount an event does not engender learning. Seeing the frame, and not the picture, is crucial. Thus, we argue for a reflection that takes into account a critical analysis of the behaviors and mindset of the individual relative to inequitable practices found in the literature.

\section{Models of Reflection}

John Dewey is attributed with a maxim in experiential learning theory: "We do not learn from experience. We learn by reflecting on experience." Kolb's (1984) four-phase experiential learning cycle in adult education has been influential in formalizing the phases of thinking in how participants should engage in the process of moving from a field experience to full integration and generalization of theoretical principles. From the initial experience, the participant should reflect on the events, conceptualize to make generalizations, and formulate a hypothesis in order to develop a plan to test the hypothesis. The cycle then resumes with a new set of experiences. However, relatively few people are good at reflecting; many are not particularly adept, often confusing a recounting of an event for true reflection that becomes a catalyst for action.
Moon (2004) sought to further unpack the process of reflection through the development of a five-stage model of reflective writing. The first stage is noticing, which is the initial representation of an event or experience and is primarily impressionistic in nature. The second is making sense, which is the first effort to apply a level of coherence to the event so that it is organized and understood by others. Moon notes that these first two stages are not reflective, but rather an early attempt to organize, and a necessary precursor for deeper processing and planning. Moon's third stage signals the beginnings of critical thinking and is described as making meaning. Participants in this stage are beginning to adopt a more holistic view of the event, including seeking influences that may not have occurred within the view of the participant. The fourth stageworking with meaning-is critical. The participant is now considering theoretical constructs and linking experiences to more formal organized theories. Importantly, the writer is posing questions to him or herself, speculating on other possible outcomes, and reading both with and against the grain of the experience to locate a new perspective. The fifth and final stage of Moon's model is transformative learning, in which the participant adopts new and creative responses to the experiences that that require the developing of a plan of action. Two major intentions of this model are salient in the context of principal preparation. First, it slows down the event by encouraging the candidate to process with intention, thus avoiding the common error made by novice school leadersreactivity rather than proactivity. Second, the model promotes a structured path for developing the specific metacognitive skills necessary to engage in reflective thinking.

\section{Reflective Writing Applications in Educational Leadership}

In higher-education courses, reflective writing is regarded as a means to improve students' lifelong learning and professional practice (Rogers, 2001; Ryan, 2011). Although reflective writing is widely accepted and valued in educational circles, a criticism is that it is complex, rhetorically demanding, and difficult to master unless taught in an explicit and systematic manner (Ryan, 2011).

A common application of reflection in educational leadership programs requires reflective writing about qualitative and quantitative data. Farrell and Marsh (2016) identify "having students reflect on their data" as an effective educational leadership practice (p. 449). This data-reflection practice is what some scholars and researchers identify as data-informed leadership in education (Knapp, Swinnerton, Copland, \& 
Monpas-Huber, 2006). Thus, this data-informed leadership engagement requires "leaders themselves [to] reflect on data to improve student, professional, or system learning" (Farrell \& Marsh, 2016, p. 426).

Furman (2012) argues that reflective writing is a valuable tool for educational leadership students to develop a growth plan based on their self-reflections, further suggesting that students engage in writing and sharing cultural autobiographies. Furman (2012) argues that "autobiographies are a powerful tool for engaging leadership students in the exploration of their culturally based identities, values, assumptions, and biases and how these impact their leadership work in schools" (p. 206). Scholars have noted that although there is an emerging engagement with self-reflection and self-reflective writing, and many examples across disciplines and practices that point to its values and benefits; there is a lack of empirical evidence regarding the effectiveness of reflective writing interventions (Naber \& Wyatt, 2014).

Scholars have demonstrated that the value of reflective writing is in naming explicitly one's aims and purposes. Further, they note that avoidance of critical self-reflection can reproduce the status quo and other oppressive and inequitable contexts and outcomes (Fendler, 2003; Ryan, 2011). This was what occurred in DeMatthews' case study of three principals' decisionmaking processes regarding social justice leadership. He found that despite good intentions, "[e]ach principal was somewhat slow to critically reflect on their practices and how their leadership possibly created a wake of injustice for certain students" (2016, p. 556).

There is a common notion that reflection, selfreflection, critical self-reflection, reflective-dialogue, data-informed leadership and reflective practice are thus inherently understood and that engagement with them can lead to systemic and sustained change. However, deploying reflection with the same fervor across diverging ideological, methodological approaches, goals, values and norms can and will drive educational leadership preparation and reform back to where they started.

\section{Context of Study}

In July 2016, the Wallace foundation launched the University Principal Preparation Initiative (UPPI), an educational leadership initiative. The UPPI was a four -year \$48.5 million investment in support of seven universities, state and school district partners, and mentor programs aimed at redesigning the universities' principal preparation programs. In its first-year report of UPPI implementation, it was noted that selfreflection was foundational to program redesign (Wang et al., 2018). Curriculum redesign sought to create tighter alignment between courses and clinical experience and to incorporate district perspectives and needs. Self-reflection became valued for its potential to build off of the professionalism and experiences of adult learners, as "adult learners often bring prior work-related experiences to the classroom, and thus may be able to engage in reflection based on experience" (Wang et al., 2018, p. xiv).

San Diego State University was one of the seven universities chosen by Wallace and it was from that work that our engagement with self-reflective writing emerged. In addition to course completion and clinical fieldwork through an approved program, candidates in California are required to pass a performance assessment beginning in the 2019-20 academic year. This performance assessment consists of three domains, referred to as leadership cycles, which can be completed in any order throughout the program:

- Leadership Cycle 1: Analyzing Data to Inform School Improvement and Promote Equity

- Leadership Cycle 2: Facilitating Communities of Practice

\section{- Leadership Cycle 3: Supporting Teacher Growth}

Each cycle is organized across four inquiry phases: Investigate, Plan, Act, and Reflect. Candidates submit written responses and video recorded evidence to demonstrate their competence in each phase as it relates to the domain.

San Diego State University participated in the pilot test (2016-17) and two years of field testing (201719) to learn about the assessment and more ably prepare candidates for school leadership positions. The results received from the California Commission on Teacher Credentialing (CTC) are not specific to the individual candidate, as these were non-consequential years designated for field testing. However, we did receive program results. Although candidates as a whole performed reasonably well, we noted that a specific area of struggle was on the reflection portion of each cycle. Based on this, we reviewed candidate submissions on our online learning management system, specifically their reflection tasks, and noted that our students were more often summarizing their experiences rather than engaging in true reflection about those experiences.

Noting the potential and value of reflection and reflective writing, we set out to develop tools and tasks to guide these aspiring administrators so that they could learn from the experiences provided to them. We decided to strengthen our students' skills in their realm for two reasons. The first is a practical 
one-we wanted to ensure their success on what will be a high-stakes assessment beginning in 2019-20. The second, with deeper implications for our preparation program, is to prepare equity-driven leaders who notice, confront, advocate, and support.

\section{Methods}

Using the work on experiential learning pioneered by Kolb (1984) and further expanded by Moon (2004), we and other members of the educational leadership faculty and our district partners developed a reflective writing rubric for use by candidates in the 2018-19 academic year (see Figure 1). The reflective writing rubric served as a frame across the program to promote critical analysis of the field experiences assigned to students. At SDSU, our field experiences are designed to mimic the real work of a principal and are consequential in nature.

\section{Procedures}

The program re-design at SDSU, funded by the Wallace Foundation, includes monthly, day-long meetings attended by the educational leadership faculty, senior leaders from three large, urban partner school districts, and several designated site leaders from those districts. This group has addressed many topics over the years, including the program focus (equity-driven leadership), recruitment and selection, course sequencing, clinical field experiences, and exit exams. Detailed notes for each of these meetings were taken by a research associate. These notes were shared with the attendees for fact checking and were revised and approved accordingly. We used these notes to identify themes as the group focused their collective efforts on teaching reflection.

When several faculty members reported to the group that they had scored the pilot performance assessment and that candidates' ability to reflect were limited, the group was interested to know if our candidates had this skill. The pilot scoring did not identify the preparation program. The group decided to explore this by first reviewing writing samples from randomly selected students. We downloaded samples from the learning management system and asked students if we could share their work with the team. These samples indicated that students were summarizing their experiences but not deeply reflecting on those experiences. The group decided to develop a tool that would provide candidates information about the expectations for reflections. We identified areas of need and developed the indicator column of our reflective writing rubric. During the second meeting, we developed draft descriptors for each of the indicators. We then shared the draft with students and had them write a reflection in class based on a recent field experience. The group then analyzed student samples and drafted the second version of the rubric. When we had produced the third version of the rubric, we invited a group of students into a fishbowl to talk about their experiences learning about reflection so that the team could listen.

Over the course of two semesters, students wrote reflective assignments based on course-specific experiences using the rubric. Candidates received feedback from course professors using the writing rubric as the primary means of conveying the success criteria for the reflective portion of the course assignment. As one example, students in the Instructional Leadership course, which focused on coaching skills, analyzed samples of teachers' reflective writing using the same rubric. In the Professional Growth Leadership course, the rubric was used to guide development of written reflections on planning, design, and implementation assignments related to professional learning at the candidate's school site. The student writing from their coursework is not the focus of this article. Rather, we focus on the development of the tool and the impact that this had on students' scores on the performance assessment.

At the end of the school year, the team met and produced the final version of the rubric, which appears in Figure 1.

\section{Data Analysis}

We collected aggregate scores by rubric on the California Administrator Performance Assessment to determine if students were increasingly successful in their ability to write a reflection. The first task included eight rubrics, the second task has seven rubrics, and the third task has seven rubrics. The last rubric for each task, scored on a scale from 1 (lowest) to 5 (highest), focused on the candidate's reflection on the experience. In our analysis, we only focus on the aggregate scores for the final rubric and so limit the analysis to reflection. We used an independent $t$-test to compare results as we only have average performance on the rubric and the number of candidates who participated. In addition, the individuals who participated each year were different. We recognize that assessment data can be problematic but decided to use it as the inability to pass this assessment would strangle the pipeline of leaders in California. In addition, we reviewed notes from all of the team meetings that focused on reflection. We independently coded the meeting notes. We shared our codes as a team and identified themes that represented the process of developing the tool. 


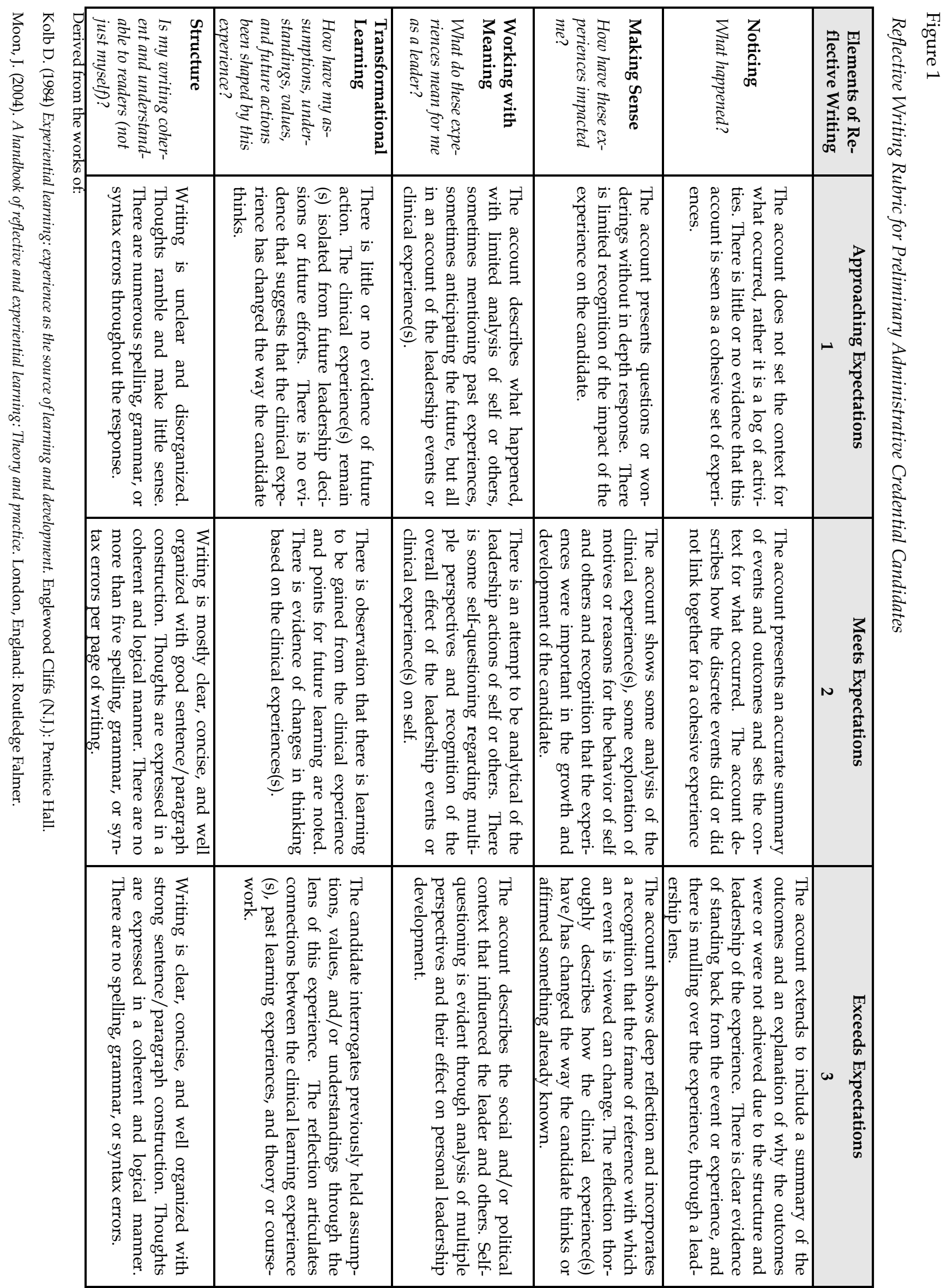




\section{Results}

In terms of student success on the state assessment, the specific focus on reflecting, including opportunities to practice this as part of course work and the development of indicators, seemed to improve their performance. On the first task, which required students to analyze data from their school, identify equity gaps, and propose interventions, student performance increased from an average of 1.32 to $3.21(t=7.57, p$ $<.0001$ ). On the second task, which required students to facilitate a community of practice based on the data that were analyzed, student performance increased from an average of 1.98 to $3.76(t=8.34, p<.0001)$. And on the third task, which required that candidates engage in a coaching cycle with a teacher, student performance increased from an average of 2.06 to 3.11 $(\mathrm{t}=3.53, \mathrm{p}<.001)$.

Over the course of the year, the team - comprised of university faculty, senior district leaders, and site administrators - struggled to create a meaningful process that would scaffold students' ability to reflect. The first issue could be considered denial that evolved to an acceptance of the responsibility to teach reflection if we expect candidates to reflect. As one of the central office leaders noted, "How do they not know how to do this? They've been teaching for at least four years to start this program. And they were nominated by their administrators." The team seemed to admire the problem for a while, until a site administrator from a different district said, "I'm not sure that I would do well on this assessment. I was not taught to write or think like this. My day is packed full. I make decision after decision. Yes, I reflect but now that I'm thinking about it, it's less about what I learned and more about what I need to do next. I think we need to directly teach this to the folks so that we can change their world views." By the end of the meeting, the team had agreed that we had to teach reflection rather than expect reflection. And each faculty member agreed to integrate the rubric and at least one task that required reflection into their course.

Another theme that emerged from the experience centered on the tasks that candidates were required to complete as part of their preparation program. In previous team meetings, we had developed tasks that candidates would complete. We believed that these were consequential, authentic, and would evoke emotional responses. But the development of this rubric led to a different conversation. As one of the faculty members noted, "We make everyone have the same experiences and then we want them to reflect. Maybe we need to provide some options so that they can make a choice about the experiences. They can choose with their university supervisor and mentor principal, but maybe we need to consider the different experiences they have and then craft experiences that will allow them to learn." During this meeting, the field experiences that would be used as fodder for the reflections were revised. The team agreed to a set of experiences that all candidates would have, specifically focused on the tasks required in the Cal-APA. In addition, they agreed to a number of choice tasks that would allow candidates an opportunity to select experiences that would contribute to their learning. The theory, as explained by one of the central office leaders was "to close the gaps in their learning. By differentiating tasks based on where each candidate was at the time, we are closer to creating just-in-time learning and their reflections will likely be stronger as a result."

A final theme to emerge was the idea that these reflections could foster the equity mindset we hoped to create in our candidates. As one of the central office leaders noted, "If we can really get them to think deeply about the work, which is to create equitable schools for all students, and they learn to reflect on what is working and what is not working, change might actually happen." As the revisions to the rubric continued, the team added specific language to provoke this type of thinking. More specifically, the rubric requires that the candidate "interrogates previously held assumptions, values, and/or understandings through the lens of this experience." During the fishbowl with students, they noted that this was the hardest thing to do. As one of them said, "It's way easier to talk about what happened and how the experience changed you. But, to really have to say, in writing, how you are interrogating your assumptions and values really pushes your thinking. The first time, I didn't have anything to say about that. But once we all shared examples, I realized that I was just afraid to name my bias and deal with the issues. It took some practice and confidence, but I'm way better at it now." In response, one of the central office leaders said, "And that thinking is what I'm looking for in people that I hire to run schools. I want you to always check your beliefs and values and make ethical decisions that respect our learners."

\section{Limitations}

This work is limited due to a relatively short amount of time attached to our work in redesigning our principal preparation program that began in 2016. The value of self-reflection emerged over time, through trial and error, and it was determined that selfreflection was pivotal to the development of leaders in education. Furthermore, there have only been three cohorts as part of our curriculum redesign and 
not all of our students have advanced into leadership positions; and the few that have are still finding their way. In addition, our department just recently, Fall 2018, introduced a course redesigned specifically targeting self-reflection. Future studies should revisit and observe our former candidates as leaders; their schools, as well interview them and their staff to better gauge how much of the self-reflective techniques were utilized over the years. In addition, these future studies and their findings will add to the knowledge base of self-reflection in educational leadership.

\section{Discussion}

In this paper we argued that learning by reflecting on an experience is both basic and essential (Boud et al., 2013; Hart, 1993; Schön, 1983). We extend these arguments as crucial parts of learning in educational leadership preparation programs. In spite of the often times antagonistic dichotomy between the hard sciences and the humanities, we see reflection, a fundamentally identifiable humanities-oriented concept and tool, as integral to learning irrespective of its engagement with the humanities or science.

\section{Increased Awareness}

The increased awareness that was found in this study we attributed to narrowing the focus of our candidates to inequity in their schools, and the role that they may have and or did play in maintaining inequities (Kolb, 1984). Furthermore, candidates were required to grapple with the ways that they may have contributed to inequity by being neutral toward oppressive structures, systems, mindsets and or discourses in their school culture and engagement with colleagues. Most of the candidates were honest with themselves during reflective assessments and assignments. Candidates were required to take a course designed specifically to help them highlight concepts and practices that maintain and reify inequity in schools. Candidates were asked to use these concepts to analyze themselves and their own practices along with the norms and expectations found in their own schools (Moon, 2004).

\section{Reifying Inequity Through Reflection}

Transformational reflection does not just happen. Instead, the aims and goals of reflection have to be explicitly named and identified. The explicitly named and identified goal of reflection acts as a criterion or as an object to be measured against. Failing to establish clear criteria by explicitly naming the goal of the reflection can and often does reproduces undesired affects; the status quo and other oppressive and inequi- table outcomes. The two contrasting district leader perspectives regarding the trouble that candidates were having with reflective writing was revealing (Rogers 2001; Ryan, 2011). One district leader seemed to suggest that simply because candidates had been identified as exemplary teachers with leadership qualities that inherently suggested that reflection and selfreflective writing should have come easily. The other district leader, however, seemed to identify why our candidates were having trouble with reflective writing noting that $\mathrm{s} / \mathrm{he}$, much like our candidates, was not trained or taught to think reflectively. Instead, the second district leader reflected that the training and thinking, s/he received was geared around problem solving and management. What became apparent in this finding is also supported by the literature on critical self-reflection; the possibilities of reproducing inequity when reflection is not explicitly defined (DeMatthews, 2016), measurable, and taught in a systemic manner (Fendler, 2003; Ryan, 2011).

\section{The Stream of Consciousness and Reflection}

We were able to identify and seize an opportunity to benefit from candidates' stream of consciousness and unique thoughts and points of emphasis by differentiating the tasks that were asked of them. Instead of imposing upon candidates a single task, which perhaps may resonate more loudly with some candidates over others, we identified various scenarios and gave candidates the latitude to choose. This approach was more effective and impactful as candidates are part of unique and specific cultures and communities relative to their school context. Each school context and culture has specific nuances and specifics in spite of demographic similarities related to SES, race/ethnicity, or English learners. Furthermore, candidates have different subjectivities, histories, cultures, and epistemologies that they bring with them into their schools. Our candidates are informed by their subjectivities, which impact what and how they see as well as what they prioritized (e.g., Schön, 1983). Thus, our objective of reflective writing allowed our candidates to engage with their subjectivities in new and eye-opening ways (Fendler, 2003; Furman, 2012; Hoover, 1994; Ryan, 2011).

\section{Implications}

Although there is not a great deal of literature on the impact of reflective writing, connecting the literature on reflection and self-reflection across academic research and practice allowed us to conceptualize and examine the potential of self-reflective writings' currency in a principal preparation program redesign. 
Because of the significant impact that reflective writing had on our candidates we caution other principal preparation programs of merely including selfreflective writing and similar reflective concepts into their principal preparation programs. It should be emphasized that the relationships with our district partners, their input and the shared learning that went into designing our principal preparation program was pivotal to the success that we found in our candidates. Candidates' willingness to buy into our program redesign was emphasized by strong relationships with key stakeholders and possible employers all of whom were invested in our redesign. We encourage educational leadership departments to invest in building relationships with district partners as this has proven to be solid ground toward candidate buy-in.

The type of awareness found in our study can really set the tone for the types of systemic change that educational leaders can impact in schools. Reflection with a stated goal of changing something very specific and writing about it is something that should be explored further specifically as relates to principal preparation programs and preparing future leaders to examine their biases and how those biases inform their practice. And lastly, building upon the unique epistemologies and cultural capital of diverse leaders can pay significant dividends. The various different voices and perspectives, backgrounds and understandings must be brought to bear in ways that reflect the changing landscape of our student populations, which are increasingly becoming more racially and ethnically diverse; leadership personnel as well as mindsets must similarly reflect that diversity.

\section{Conclusions}

It seems obvious, but if leadership preparation programs must teach the skills and dispositions critical to effective operations of schools, we realize that our candidates are not reflecting on their experiences and set out to change that. The result was a series of experiences that provoked their thinking as well as a tool that was integrated into each class so that future leaders would develop the skill of reflection. It seems to have worked, at least as measured by external examiners on a high-stakes assessment. Future work will need to explore these graduates' ability to hone their reflection skills on the job as they engage in the real work of leading schools.

\section{References}

Boud, D., Keogh, R., \& Walker, D. (Eds.). (2013). Reflection: Turning experience into learning. New York: Routledge.
Bowman, M., \& Addyman, B. (2014). Academic reflective writing: A study to examine its usefulness. British Journal of Nursing, 23(6), 304-309.

Bryk, A. S., Sebring, P. B., Allensworth, E., Luppescu, S., \& Easton, J. Q. (2010). Organizing schools for improvement: Lessons from Chicago. Chicago: University of Chicago Press.

Campbell, R. F. (1979). A critique of the Educational Administration Quarterly. Educational Administration Quarterly, 15(3), 1-19. https:// doi.org/10.1177/0013131X7901500303

Coleman, D., \& Willis, D. S. (2015). Reflective writing: The student nurse's perspective on reflective writing and poetry writing. Nurse Education Today, 35 (7), 906-911. https://doi.org/10.1016/ j.nedt.2015.02.018

DeMatthews, D. (2016). Social justice dilemmas: Evidences on the successes and shortcomings of three principals trying to make a difference. International Journal of Leadership in Education, 21(5), 545-559.

Egalite, A. J., Fusarelli, L. D., \& Fusarelli, B. C. (2017). Will decentralization affect educational inequity? The Every Student Succeeds Act. Educational Administration Quarterly, 53(5), 757-781. https:// doi.org/10.1177/0013161X17735869

Farrell, C. C., \& Marsh, J. A. (2016). Metrics matter: How properties and perceptions of data shape teachers' instructional responses. Educational Administration Quarterly, 52(3), 423-462. https:// doi.org/10.1177/0013161X16638429

Fendler, L. (2003). Teacher reflection in a hall of mirrors: Historical influences and political reverberations. Educational Researcher, 32(3), 16-25. https:// doi.org/10.3102/0013189X032003016

Furman, G. (2012). Social justice leadership as praxis: Developing capacities through preparation programs. Educational Administration Quarterly, 48(2), 191-229. doi.org/10.1177/0013161X11427394

https://

Hart, A. W. (1993). Reflection: An instructional strategy in educational administration. Educational Administration Quarterly, 29(3), 339-363. https:// doi.org/10.1177/0013161X93029003007

Hoover, L. A. (1994). Reflective writing as a window on preservice teachers' thought processes. Teaching and Teacher Education, 10(1), 83-93. https:// doi.org/10.1016/0742-051X(94)90042-6

Khalifa, M. (2018). Culturally responsive school leadership. Retrieved from http://hepg.org/hep-home/ books/culturally-responsive-school-leadership

Knapp, M. S., Swinnerton, J. A., Copland, M. A., \& Monpas-Huber, J. (2006). Data-informed leadership in education. Center for the Study of Teaching and Policy: University of Washington. 
Kolb D. (1984) Experiential learning: experience as the source of learning and development. Englewood Cliffs, New Jersey: Prentice Hall.

Kottkamp, R. B. (2011). Introduction: Leadership preparation in education. Educational Administration Quarterly, 47(1), 3-17. https:// doi.org/10.1177/0011000010378609

Lindle, J. C. (2009). Book review: Truitt, T. E. (2006) Brick walls: Reflections on race in a Southern school district. Educational Administration Quarterly, 45(1), $152-159$. $\mathrm{h}$ t $\mathrm{t} \mathrm{p} \mathrm{s}$ : / / doi.org/10.1177/0013161X08327560

Mahlanze, H. T., \& Sibiya, M. N. (2017). Perceptions of student nurses on the writing of reflective journals as a means for personal, professional and clinical learning development. Health SA Gesondheid, 22, 79-86. https://doi.org/10.1016/j.hsag.2016.05.005

Marshall, J., \& Fisher, D. (2018). Making preparation practical: Reducing aspiring administrator time to competence through five types of leaderly thinking. Journal of School Administration Research and Development, 3(1), 74-80.

McGuire, L., Lay, K., \& Peters, J. (2009). Pedagogy of reflective writing in professional education. Journal of the Scholarship of Teaching and Learning, 9(1), 93-107.

Moon, J. (2004). A handbook of reflective and experiential learning: Theory and practice. London, England: Routledge Falmer.

Naber, J., \& Wyatt, T. H. (2014). The effect of reflective writing interventions on the critical thinking skills and dispositions of baccalaureate nursing students. Nurse Education Today, 34(1), 67-72. https:// doi.org/10.1016/j.nedt.2013.04.002

Pounder, D. G., \& Johnson, B. L. (2007). Reflections on EAQ's past, present, and future. Educational Administration Quarterly, 43(2), 259-272. https:// doi.org/10.1177/0013161X06298593

Rogers, R. R. (2001). Reflection in higher education: A concept analysis. Innovative Higher Education, 26 (1), 37-57. https://doi.org/10.1023/ A:1010986404527

Ryan, M. (2011). Improving reflective writing in higher education: A social semiotic perspective. Teaching in Higher Education, 16(1), 99-111. https:// doi.org/10.1080/13562517.2010.507311

Schön, D. A. (1983). The reflective practitioner: How professionals think in action. Basic Books. London: Routledge.

Schwartz, A. W., Abramson, J. S., Wojnowich, I., Accordino, R., Ronan, E. J., \& Rifkin, M. R. (2009, August 1). Evaluating the impact of the humanities in medical education. Mount Sinai Journal of Medicine, 76(4), 372-380. https://doi.org/10.1002/msj.20126
Short, P. M., \& Rinehart, J. S. (1993). Reflection as a means of developing expertise. Educational Administration Quarterly, 29(4), 501-521. https:// doi.org/10.1177/0013161X93029004006

Wang, E. L., Gates, S. M., Herman, R., Mean, M., Perera, R., Tsai, T., Whipkey, K., \& Andrew, M. (2018). Launching a redesign of university principal preparation programs: Partners collaborate for change. Santa Monica, CA: Rand.

\section{Authors}

James Wright, $\mathrm{PhD}$, serves as an assistant professor at San Diego Sate University, in the Department of Educational Leadership. He can be contacted at 5500 Campanile, San Diego, CA., 921182. His research focuses on culturally responsive school leadership.

Douglas Fisher, $\mathrm{PhD}$, is a professor of educational leadership at San Diego State University, San Diego, CA, 92812. Doug's research interests center on instructional improvement, and he is the author of the book All Learning is Social and Emotional.

Nancy Frey, PhD, is a professor of educational leadership at San Diego State University, San Diego, CA, 92812. Nancy's research interests center on access to quality instruction and responses to intervention. She is the author of the book Building Equity. 